\title{
Protective effect of quercetin on bupivacaine-induced neurotoxicity via T-type calcium channel inhibition
}

\author{
Chao Jin ${ }^{1}$, Huisheng $\mathrm{Wu}^{1}$, Chaoliang Tang ${ }^{2}$, Jianjuan $\mathrm{Ke}^{1}$ and Yanlin Wang ${ }^{1 *}$ \\ ${ }^{1}$ Department of Anesthesiology, Zhongnan Hospital of Wuhan University, ${ }^{2}$ Department of Anesthesiology, Renmin Hospital of \\ Wuhan University, Wuhan, Hubei PR, China \\ *For correspondence: Email: yaalinwang@163.com
}

\begin{abstract}
Purpose: To determine the effect of quercetin on bupivacaine-induced neurotoxicity and to investigate the mechanisms involved.

Methods: Cultured SH-SY5Y cells were divided into five treatment groups: control group with no drug, bupivacaine treatment group, quercetin group, bupivacaine--quercetin combination treatment group, and bupivacaine-mibefradil combination treatment group. Cell morphology in each group was examined by microscopy while cell viability was assessed by 3-(4, 5-dimethyl-2-thiazolyl)-2, 5-diphenyl-2tetrazolium bromide (MTT) assay after $24 h$ incubation. Cytosolic calcium ion concentration was determined by flow cytometry while Cav3.1 protein expression was evaluated by western blot.

Results: Quercetin $(50 \mu M)$ significantly $(p<0.05)$ protected SH-SYS5 cells from bupivacaine-induced cell apoptosis and also significantly reduced intracellular calcium ion concentration $(p<0.01)$ by approximately $40 \%$. Cav3.1 protein expression was normalized following quercetin treatment.

Conclusion: These results show that quercetin reduces the neurotoxicity induced by bupivacaine, possibly through inhibition of T-type calcium channel. This finding implies a novel mechanism for neuroprotective effect of quercetin, and its potential for treating toxicity arising from the use of local anesthetic agents.
\end{abstract}

Keywords: Quercetin, Bupivacaine, Local anaesthetic, Neuroprotection, Neurotoxicity, T-type calcium channel

Tropical Journal of Pharmaceutical Research is indexed by Science Citation Index (SciSearch), Scopus, International Pharmaceutical Abstract, Chemical Abstracts, Embase, Index Copernicus, EBSCO, African Index Medicus, JournalSeek, Journal Citation Reports/Science Edition, Directory of Open Access Journals (DOAJ), African Journal Online, Bioline International, Open-J-Gate and Pharmacy Abstracts

\section{INTRODUCTION}

Local anesthetic agents are widely used in hospitals; however they are also associated with certain side effects, especially neurotoxicity. It has been shown that neurotoxicity caused by local anesthetics such as lidocaine and bupivacaine are related to changes in calcium homeostasis, resulting in intracellular calcium overload [1]. Calcium homeostasis is regulated by many different kinds of calcium channels such as the ligand-gated calcium channels and voltage-gated calcium channels (VGCCs) [2].
VGCCs are categorized into two types: high voltage-activated calcium channels (e.g. $\mathrm{L}$ and $\mathrm{N}$-type calcium channel), and low voltageactivated calcium channels (T-type calcium channel; T represents transient) [3]. Recent studies indicated that blocking T-type calcium channels or inhibiting its activation protected neurons against apoptosis under severe conditions [4].

Quercetin (chemical structure given in Figure 1) is a bioflavonoid widely found in many fruits and leaves, and it has been used as health supplement claimed to prevent or treat a variety 
of diseases, although there are no clinical data to back these claims [5]. However, extensive cell and animal-based studies have demonstrated its many efficacies including anti-oxidative, antiinflammatory and anti-tumor properties $[6,7]$.

The current study is focused on the protective effect of quercetin on neurons against bupivacaine-induced neurotoxicity. The effect of quercetin on the expression of T-type calcium channels was also evaluated to investigate the likely mechanism involved.

\section{EXPERIMENTAL}

\section{Materials}

The cell line (SH-SY5Y) was bought from Shanghai Institute for Biological Sciences (Shanghai, China). Mibefradil dihydrochloride, bupivacaine hydrochloride, quercetin and MTT were products of Sigma (St. Louis, MO, USA). Anti-Cav3.1 mono-clonal antibody, anti- $\beta$-actin mono-clonal antibody and horseradish peroxidase-conjugated polyclonal antibody were purchased from Santa Cruz (Santa Cruz, CA, USA). DMEM/F12 medium and fetal bovine serum (FBS) was from Gibco (Grand Island, NY, USA). Fluo-8® AM ester was bought from AAT Bioquest Inc. (Sunnyvale, CA, USA). All other reagents purchased from commercial vendors were of analytical grade.

\section{Cell culture, cell morphology and cell viability assay}

SH-SY5Y cells were cultured in DMEM/F12 medium with $10 \%$ FBS, (with $150 \mu \mathrm{g} / \mathrm{mL}$ streptomycin and 150 units $/ \mathrm{mL}$ penicillin) at 37 ${ }^{\circ} \mathrm{C}$ in a humidified $\mathrm{CO}_{2}$ incubator. The medium was replaced every other day. To examine the effect of quercetin on bupivacaine-induced neurotoxicity, cultured SH-SY5Y cells were divided into five groups: control group (C), bupivacaine (1 mM) group (B), quercetin $(50 \mu \mathrm{M})$ group $(\mathrm{Q})$, quercetin $(50 \mu \mathrm{M})$ with bupivacaine $(1$ $\mathrm{mM})$ group $(\mathrm{Q}+\mathrm{B}$, and mibefradil $(10 \mu \mathrm{M})$ with bupivacaine (1 $\mathrm{mM})$ group $(\mathrm{M}+\mathrm{B})$. In the quercetin $(50 \mu \mathrm{M})$ with bupivacaine $(1 \mathrm{mM})$ group and the mibefradil $(10 \mu \mathrm{M})$ with bupivacaine $(1$ $\mathrm{mM}$ ) group (M+B), $50 \mu \mathrm{M}$ of quercetin or $10 \mu \mathrm{M}$ mibefradil was added to cell culture media $2 \mathrm{~h}$ prior to bupivacaine (1 mM) exposure. After $24 \mathrm{~h}$ incubation, the cells in the wells in each treatment group were placed under a microscope (IX73, Olympus) for cell morphology observation. The cell images were captured by digital camera at $100 x$ magnification.

Cell viability in each treatment group was determined by MTT viability assay. Generally, the cells were seeded into 96-well plates (four thousand cells per well) with $200 \mu \mathrm{L}$ culture media per well, and incubated overnight before drug treatment. On the next day, the culture medium was changed with $200 \mu \mathrm{L}$ fresh media containing appropriate drug(s). The cells were incubated for another $24 \mathrm{~h}$ before MTT addition $(20 \mu \mathrm{L})$. After $4 \mathrm{~h}$, the absorbance of each well in the 96-well plate was measured at $570 \mathrm{~nm}$ in a microplate reader (Fisher Scientific, Waltham, MA, USA). The mean absorbance of the control, untreated group was set as $100 \%$ cell survival and the cell viability in every other treatment group was calculated relative to the control.

\section{Determination of intracellular calcium ion concentration}

Intracellular calcium ion concentration was analyzed using commercially available Fluo- $8 \AA$ AM ester probe in accordance with the product instruction manual. Fluo-8® AM ester stock solution $(5 \mathrm{mM})$ was first dissolved in anhydrous dimethyl sulphoxide (DMSO). A testing solution $(10 \mu \mathrm{M})$ was then prepared with the cell culture media (without FBS) containing $0.02 \%$ Pluronic $\circledast \mathrm{F}-127$. Each $200 \mu \mathrm{L}$ of testing solution was added to the culture media in the plates with live cells (final probe concentration was kept at 5 $\mu \mathrm{M})$. After $20 \mathrm{~min}$ incubation at $25{ }^{\circ} \mathrm{C}$, the live cells were washed several times with HEPES buffer to remove free probe agent.<smiles>O=c1c(O)c(-c2ccc(O)c(O)c2)oc2cc(O)cc(O)c12</smiles>

Quercetin<smiles>COCC(=O)O[C@]1(CCN(C)CCCc2nc3ccccc3[nH]2)CCc2cc(F)ccc2[C@H]1C(C)C</smiles>

Mibefradil

Figure 1: Chemical structures of quercetin and mibefradil 
The live cells were then analyzed by flow cytometry (BD FACSCelesta ${ }^{\mathrm{TM}}$, BD Biosciences, San Jose, CA, USA) at an excitation and emission wavelength of 490 and $525 \mathrm{~nm}$, respectively. The following equation was used to calculate the intracellular calcium ion concentration (Eq 1).

$\left[C a^{2+}\right]=K_{d}^{*}\left(F-F_{\min }\right) /\left(F_{\max }-F\right)$

where $F$ represented the fluorescence intensity of the probe in each experimental group; $F_{\text {min }}$ represented the fluorescence intensity without calcium ion; and $F_{\max }$ represented the fluorescence intensity of the calcium ionsaturated probe. The dissociation constant $\left(K_{d}\right)$, reflecting the affinity of the probe for calcium, was set at the theoretical value (389 nM) as provided in the manual.

\section{Determination of Cav3.1 protein expression by western blotting}

Total protein from cells in each treatment groups was extracted to determine Cav3.1 protein expression. The sample cells were lysed and the total protein concentration in the supernatant was determined by the BCA protein assay kit (Fisher Scientific, Waltham, MA, USA). $20 \mu \mathrm{g}$ of protein from each sample was separated by $12 \%$ SDSPAGE before transferring to polyvinylidene difluoride (PVDF) membrane for western blotting. The membranes were then blocked with $5 \%$ milk (fat-free) in Tris buffered saline (containing 0.05 $\%$ polysorbate 20) for $1 \mathrm{~h}$ at $25{ }^{\circ} \mathrm{C}$, and then incubated with primary antibodies that were against Cav3.1 (1: 500) or $\beta$-actin (1: 500) overnight under gentle agitation at $4{ }^{\circ} \mathrm{C}$.

Thereafter, the membranes were incubated with secondary antibody (horseradish peroxidaseconjugated IgG, 1:1000) for another $1 \frac{1}{2} \mathrm{~h}$ at 25 ${ }^{\circ} \mathrm{C}$. The membranes were washed three times with Tris buffered saline, after which they were developed by enhanced chemiluminescence (ECL, Thermo Scientific, Shanghai, China) followed by exposure to X-ray films. The films were then scanned to visualize the protein bands.

\section{Statistical analysis}

All data are expressed as mean \pm standard deviation (SD), and were analyzed using SPSS 18.0 software. One-way ANOVA test with Tukey post-test was performed for multiple comparisons. $P<0.05$ was considered statistically significant.

\section{RESULTS}

\section{Effect of quercetin on cell morphology}

No substantial morphological difference was found in the SH-SY5Y cells treated with quercetin when compared with the control group (Figure 2). However, after exposure to bupivacaine ( $1 \mathrm{mM})$ for $24 \mathrm{~h}$, most cells became abnormal: they were inflated and more rounded in shape; detached and floating cells were easily observed. A small percentage of cells in the quercetin-bupivacaine co-treatment group, as well as a fraction of cells in the mibefradilbupivacaine co-treatment group also showed abnormal cell morphology as the cells in bupivacaine-only group. However, the majority of the cells in the two co-treatment groups appeared normal, like cells in the control group (Figure 2).

\section{Cell viability}

There were no significant differences in the cell viabilities between the control group after $24 \mathrm{~h}$ (C-24) and quercetin-treated group after $24 \mathrm{~h}(\mathrm{Q}$ 24) (113.2 $\pm 19.7 \%$ and $103.6 \pm 16.8 \%$, respectively, Figure 3 ). The cell viabilities in the bupivacaine-only group (B-24), the quercetinbupivacaine co-treatment group $(\mathrm{Q}+\mathrm{B}-24)$ and the mibefradil-bupivacaine co-treatment group $(\mathrm{M}+\mathrm{B}-24)$ after $24 \mathrm{~h}$ were $31.3 \pm 3.5 \%, 61.7 \pm$ $2.9 \%$ and $61.8 \pm 8.7 \%$, respectively. The cell viabilities in B-24, $\mathrm{Q}+\mathrm{B}-24$ and $\mathrm{M}+\mathrm{B}-24$ groups were significantly decreased when compared to the control ( $p<0.05$; Figure 3 ). However, the cell viabilities in the quercetin-bupivacaine cotreatment group $(\mathrm{Q}+\mathrm{B}-24)$ and cell viability in the mibefradil-bupivacaine co-treatment group ( $\mathrm{M}+\mathrm{B}-$ 24) were significantly higher than that in the bupivacaine-only group (B-24) $(p<0.05$; Figure $3)$. Both quercetin and mibefradil protected the SH-SY5Ycells against bupivacaine-induced toxicity, leading to increased cell viability.

\section{Intracellular calcium ion concentrations}

There were no statistically significant differences in intracellular calcium ion concentrations between the control group and the quercetin-only treatment group (C-24 and Q-24) $(407 \pm 31 \mathrm{nM}$ and $416 \pm 18 \mathrm{nM}$, respectively). However, calcium ion concentration in the $1 \mathrm{mM}$ bupivacaine treatment group (B-24, $817 \pm 65 \mathrm{nM})$ was significantly $(p<0.01)$ higher than that in the control group. Both quercetin and mibefradil treatments caused significant reduction by nearly $40 \%(p<0.01)$ of the intracellular calcium ion concentration in cells exposed to bupivacaine. The cytosolic calcium ion concentrations were 
$505 \pm 36 \mathrm{nM}$ and $485 \pm 45 \mathrm{nM}$ in $\mathrm{Q}+\mathrm{B}-24$ and $M+B-24$ groups, respectively (Figure $4 A$ and Figure 4B).

\section{Intracellular calcium ion concentrations}

There were no statistically significant differences in intracellular calcium ion concentrations between the control group and the quercetin-only treatment group (C-24 and Q-24) $(407 \pm 31 \mathrm{nM}$ and $416 \pm 18 \mathrm{nM}$, respectively). However, calcium ion concentration in the $1 \mathrm{mM}$ bupivacaine treatment group (B-24, $817 \pm 65 \mathrm{nM}$ ) was significantly $(p<0.01)$ higher than that in the control group. Both quercetin and mibefradil treatments caused significant reduction by nearly $40 \%(p<0.01)$ of the intracellular calcium ion concentration in cells exposed to bupivacaine. The cytosolic calcium ion concentrations were $505 \pm 36 \mathrm{nM}$ and $485 \pm 45 \mathrm{nM}$ in Q+B-24 and $\mathrm{M}+\mathrm{B}-24$ groups, respectively (Figure $4 \mathrm{~A}$ and Figure 4B).

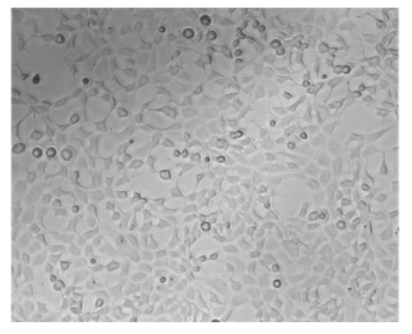

C-24

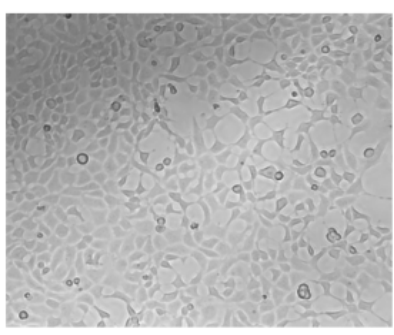

Q-24

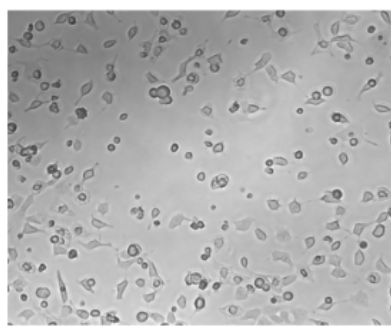

B-24

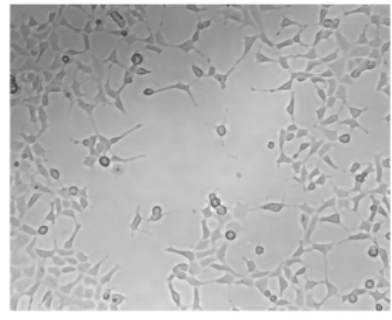

Q+B-24

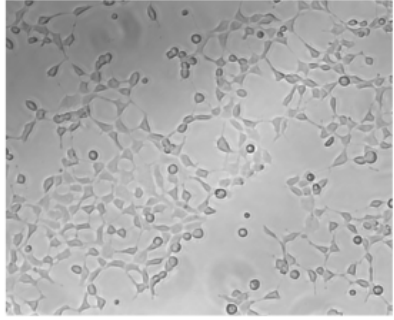

$\mathrm{M}+\mathrm{B}-24$

Figure 2: Representative cell morphologies in the different treatment groups after $24 \mathrm{~h}$. The cells were imaged under microscopy. Most cells in B-24 showed abnormal morphologies (arrow showed representative round and inflated cells) when compared to those in the control group, while cells in $\mathrm{Q}+\mathrm{B}-24$ and M+B-24 showed both normal and abnormal morphologies, even though the abnormal cells were only a small part.

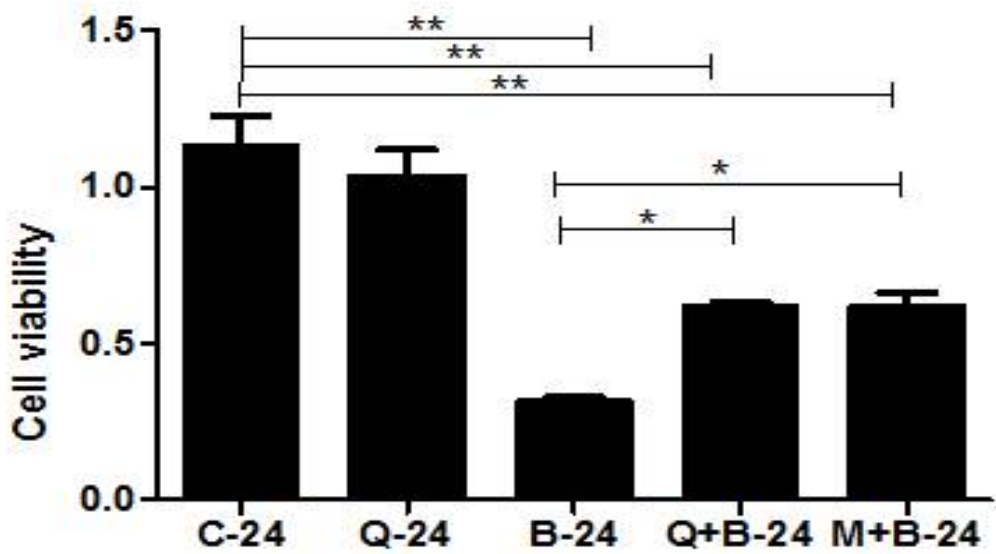

Figure 3: Cell viabilities in different treatment groups after $24 \mathrm{~h}$. The cell viability was determined by MTT assay. Cell viability was lowest in B-24 group, followed by $Q+B-24$ and $M+B-24$ groups. Data is expressed as mean $\pm \mathrm{SD}$. One-way ANOVA was used as statistical method. ${ }^{*} p<0.05$ : B-24 versus $\mathrm{Q}+\mathrm{B}-24 / \mathrm{M}+\mathrm{B}-24$; ** $p<0.01$ : C-24 versus $\mathrm{B}-24 / \mathrm{Q}+\mathrm{B}-24 / \mathrm{M}+\mathrm{B}-24$ 

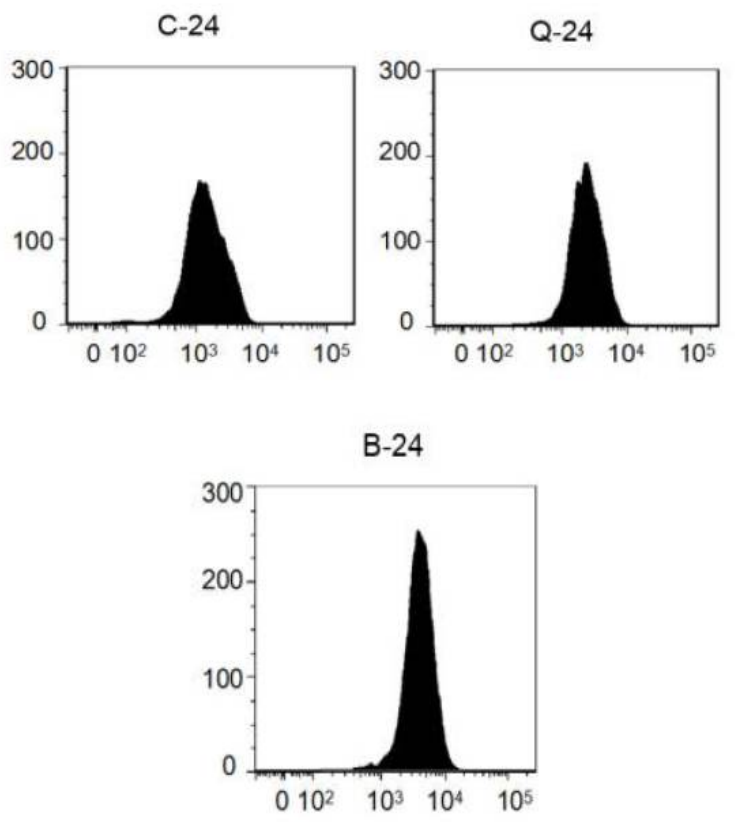

Q+B-24

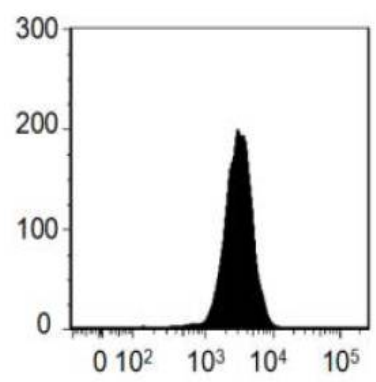

$\mathrm{M}+\mathrm{B}-24$

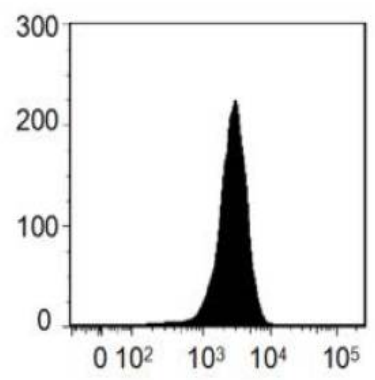

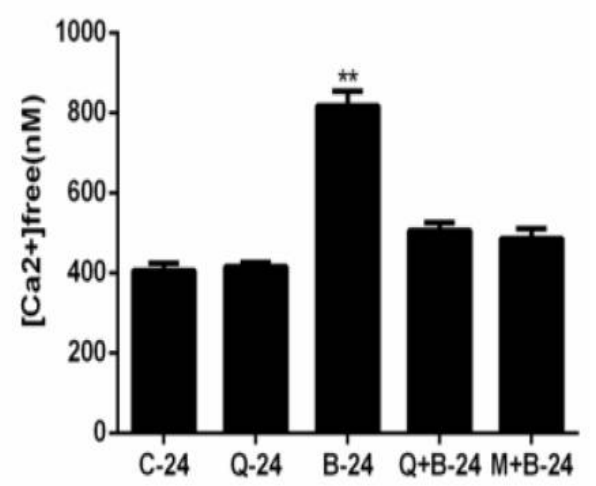

Figure 4: Intracellular calcium ion concentrations in different groups at 24 h. (A) Representative flow cytometry analysis results in each group; (B) the calculated intracellular calcium ion concentrations in each group. Data are expressed as mean \pm SD. A one-way ANOVA was used as statistical method; ${ }^{* *} p<$ $0.01 \mathrm{~B}-24$ versus control/Q+B-24/M+B-24.

\section{DISCUSSION}

It was found that T-type calcium channels might be involved in neuronal apoptosis caused by local anesthetic related toxicity and certain
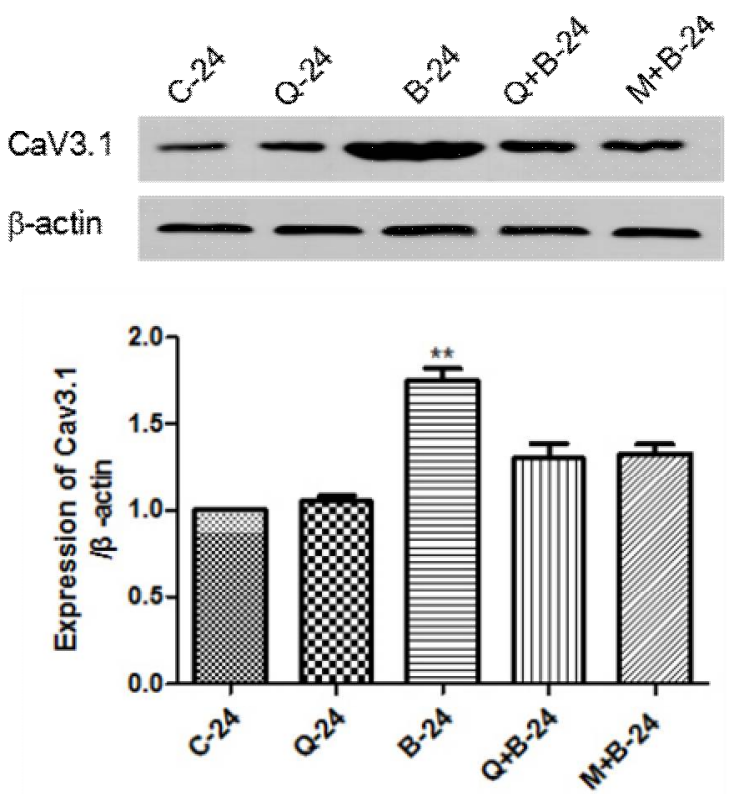

Figure 5: Cav3.1 protein expressions in each treatment group. Cav3.1 expression was detected by western blot; $\beta$-actin served as the control; Cav3.1 expression was highest in B-24, followed by $Q+B-24$ and $\mathrm{M}+\mathrm{B}-24$, and was lowest in $\mathrm{C}-24$ and $\mathrm{Q}-24$

specific T-type calcium channel blocker such as NNC 55-0396 dihydrochloride could suppress the toxicity $[8,9]$. The present study demonstrated that an herbal medicine called quercetin, at 50 $\mu \mathrm{M}$ concentration, protected SH-SY5Y cells from bupivacaine-induced cellular death, and was as effective as mibefradil, one T-type calcium channel blocker, at $10 \mu \mathrm{M}$ concentration. The neuro-protective effects of T-type calcium channel blockers (such as mibefradil) have been reported before [10]. For example, Bancila et al. found that mibefradil administration prevented neuronal death after ischemia in a global ischemia rat model [11]. The results obtained in the present study show the neuro-protective effect of mibefradil against bupivacaine-induced neurotoxicity and revealed that quercetin could also alleviate bupivacaine-induced cell damage, although at a relatively high concentration. It was also found that quercetin at $10 \mu \mathrm{M}$ did not improve the cell viability (data not shown) after bupivacaine exposure, suggesting that the protective effect of quercetin was likely concentration-dependent.

Wen et al found that the expression of Cav3.1 (the main sub-unit of T-type calcium channel) was up-regulated by lidocaine [8]. The elevated calcium channel expression mediates calcium ion influx, resulting in increased intracellular calcium ion concentration. This would trigger the phenomena called calcium-induced calcium release, giving rise to more calcium release from cellular calcium storage organelle - the 
endoplasmic reticulum. The resultant intracellular calcium overload leads ultimately to cell apoptosis [8]. In the present study, $1 \mathrm{mM}$ bupivacaine treatment effectively activated Cav3.1 expression and significantly increased intracellular calcium ion concentration. This is consistent with findings in earlier reports. However, it was found that quercetin at $50 \mu \mathrm{M}$, equivalent to mibefradil at $10 \mu \mathrm{M}$, substantially reduced Cav3.1 expression and resulted in marked decrease in cytosolic calcium ion concentration in cells exposed to bupivacaine. The calcium ion concentration in cells from either the quercetin or mibefradil treatment group was almost at par with that in the control group level.

The in vitro and in vivo applications of quercetin, an anti-oxidant flavonoid have been extensively investigated. Quercetin has been shown to exert protective effects against cardiovascular diseases like atherosclerosis and ischemia reperfusion-induced injury, as well as anti-cancer and anti-inflammatory effects [12]. Recent studies have also revealed the neuro-protective effects of quercetin in many neurodegenerative diseases such as Alzheimer's disease and Parkinson's disease, and against hypoxiainduced injury and neurotoxic chemical-induced damage [13,14]. However, the mechanisms underlying these effects were not fully understood. It was previously suggested that quercetin exerted neuro-protective effects and cellular defenses against oxidative stress via the induction of Nrf2-ARE (nuclear factor erythroid 2related factor 2-antioxidant response element) and the anti-oxidant enzyme paraoxonase 2 (PON2) [13].

In the present study, the reduced intracellular calcium ion concentration and decreased Cav3.1 protein expression in quercetin-bupivacaine cotreatment group suggest the likely involvement of the inhibition of T-type calcium channels by quercetin in the neuro-protective effect of quercetin.

\section{Study limitations}

There were some limitations in this study. In the first place, the study was conducted on $\mathrm{SH}$ SY5Y, the transformed neuroblastoma cells in vitro. The results obtained may not readily be applicable to neurons in vivo. Secondly, as an anti-oxidant, quercetin could also influence many other molecular targets and pathways such as ROS generation. It has been reported that another anti-oxidant, ginkgolide B effectively protected SH-SY5Y from bupivacaine caused apoptosis mainly through suppression of ROS accumulation [15]. The impact of quercetin's free radical scavenging property can hardly be excluded [16]. These limitations notwithstanding, the neuro-protective effect of quercetin was wellestablished in this study.

\section{CONCLUSION}

The findings of this study show that quercetin significantly reduces bupivacaine-induced neurotoxicity possibly by inhibition of T-type calcium channels. Although the detailed molecular mechanism needs to be further investigated, the present findings indicate the potential application of quercetin in the treatment of bupivacaine (and likely several other local anesthetic)-induced neurotoxicity.

\section{DECLARATIONS}

\section{Acknowledgement}

The authors acknowledge the authorities and the ethical committee of the Central Hospital, Zhumadian, Henan Province-463000, China, for their support.

\section{Conflict of Interest}

No conflict of interest associated with this work.

\section{Contribution of Authors}

The authors declare that this work was done by the authors named in this article and all liabilities pertaining to claims relating to the content of this article will be borne by them.

\section{Open Access}

This is an Open Access article that uses a funding model which does not charge readers or their institutions for access and distributed under the terms of the Creative Commons Attribution License (http://creativecommons.org/licenses/by/ 4.0) and the Budapest Open Access Initiative (http://www.budapestopenaccessinitiative.org/rea d), which permit unrestricted use, distribution, and reproduction in any medium, provided the original work is properly credited.

\section{REFERENCES}

1. Ozcan M, Ayar A, Alcin E, Ozcan S, Kutlu S. Effects of levobupivacaine and bupivacaine on intracellular calcium signaling in cultured rat dorsal root ganglion neurons. J Recept Signal Transduct Res 2010; 30: 115120. 
2. Striessnig J. Voltage-gated calcium channels - from basic mechanisms to disease. J Physiol 2016; 594: 58175821.

3. Furukawa T. Types of voltage-gated calcium channels: molecular and electrophysiological views. Curr Hypertens Rev 2013; 9: 170-181.

4. Wildburger NC, Lin-Ye A, Baird MA, Lei D, Bao J. Neuroprotective effects of blockers for T-type calcium channels. Mol Neurodegener 2009; 4: 44.

5. Russo M, Spagnuolo C, Tedesco I, Bilotto S, Russo GL. The flavonoid quercetin in disease prevention and therapy: facts and fancies. Biochem Pharmacol 2012; 83: 6-15.

6. Kashyap D, Mittal S, Sak K, Singhal $P$, Tuli HS. Molecular mechanisms of action of quercetin in cancer: recent advances. Tumour Biol 2016; 37: 12927-12939.

7. Shaik YB, Castellani ML, Perrella A, Conti F, Salini V, Tete S, Madhappan B, Vecchiet J, De Lutiis MA, Caraffa $A$, Cerulli G. Role of quercetin (a natural herbal compound) in allergy and inflammation. J Biol Regul Homeost Agents 2006; 20: 47-52.

8. Wen $X, X u S$, Zhang $Q$, Li X, Liang $H$, Yang $C$, Wang $H$, Liu H. Inhibitory gene expression of the Cav3.1 T-type calcium channel to improve neuronal injury induced by lidocaine hydrochloride. Eur J Pharmacol 2016; 775: 4349.

9. Wen X, Xu S, Liu H, Zhang Q, Liang H, Yang C, Wang $H$. Neurotoxicity induced by bupivacaine via T-type calcium channels in SH-SY5Y cells. PLoS One 2013; 8: e62942.
10. Kopecky BJ, Liang R, Bao J. T-type calcium channel blockers as neuroprotective agents. Pflugers Arch 2014; 466: 757-765.

11. Bancila M, Copin JC, Daali Y, Schatlo B, Gasche $Y$, Bijlenga $P$. Two structurally different T-type $\mathrm{Ca} \mathrm{2+}$ channel inhibitors, mibefradil and pimozide, protect CA1 neurons from delayed death after global ischemia in rats. Fundam Clin Pharmacol 2011; 25: 469-478.

12. Gormaz JG, Quintremil S, Rodrigo R. Cardiovascular Disease: A Target for the Pharmacological Effects of Quercetin. Curr Top Med Chem 2015; 15: 1735-1742.

13. Suganthy N, Devi KP, Nabavi SF, Braidy N, Nabavi SM. Bioactive effects of quercetin in the central nervous system: Focusing on the mechanisms of actions. Biomed Pharmacother 2016; 84: 892-908.

14. Costa LG, Garrick JM, Roque PJ, Pellacani C. Mechanisms of Neuroprotection by Quercetin: Counteracting Oxidative Stress and More. Oxid Med Cell Longev 2016; 2016: 2986796.

15. Li L, Zhang QG, Lai LY, Wen XJ, Zheng T, Cheung CW, Zhou SQ, Xu SY. Neuroprotective effect of ginkgolide $B$ on bupivacaine-induced apoptosis in SH-SY5Y cells. Oxid Med Cell Longev 2013; 2013: 159864.

16. Rezaei-Sadabady R, Eidi A, Zarghami N, Barzegar A. Intracellular ROS protection efficiency and free radicalscavenging activity of quercetin and quercetinencapsulated liposomes. Artif Cells Nanomed Biotechnol 2016; 44: 128-134. 